\title{
Morphological and Morphometric Study of Pterion in Adult Dry Human Skulls
}

\author{
Ananya Priya ${ }^{\circledR 1}$, Anjali Jain ${ }^{2} 2$ \\ 1Post Graduate, Department of Anatomy, Christian Medical College, Ludhiana, Punjab, India, ${ }^{2}$ Professor, Department of Anatomy, Christian Medical College, Ludhiana, \\ Punjab, India.
}

\section{Abstract}

Introduction: Pterion is significant bony landmark because it commonly lies near the anterior branch of middle meningeal artery as well as Broca's Area. The aim is to study the types of pterion and measure the distance from various bony landmarks on skull to the midpoint of pterion. Subjects and Methods: This study was performed on 70 adult dry human skulls of unknown age and sex. Types and location of pterion was observed bilaterally. Measurements were taken in millimeter using digital Vernier caliper from midpoint of pterion to i) fronto-zygomatic suture ii) middle of zygomatic arch iii) tip of mastoid process iv) glabella v) antero-superior margin of external acoustic meatus vi) Asterion. Results: We observed five types of pterion: spheno-parietal, fronto-temporal, stellate, epipteric and atypical. Among the skulls studied the most common type was sphenoparietal bilaterally. The mean of distances from midpoint of pterion to fronto-zygomatic suture was, $31.68 \pm 5.58 \mathrm{~mm}$ and $31.18 \pm 5.82 \mathrm{~mm}$; to the middle of zygomatic arch was $38.87 \pm 3.63 \mathrm{~mm}$ and $37.84 \pm 3.99 \mathrm{~mm}$; to asterion was $83.55 \pm 7.22 \mathrm{~mm}$ and $85.53 \pm 6.88$ $\mathrm{mm}$; to external acoustic meatus it was $51.70 \pm 3.20 \mathrm{~mm}$ and $51.37 \pm 3.39 \mathrm{~mm}$; to glabella it was $77.24 \pm 6.93 \mathrm{~mm}$ and $76.44 \pm 6.83 \mathrm{~mm}$; to tip of mastoid process it was $80.77 \pm 6.10 \mathrm{~mm}$ on the right side and $79.59 \pm 5.70 \mathrm{~mm}$ on the left side. Conclusion: Pterion is the most commonly used surface landmark. Findings of present study regarding classification of pterion will be helpful for neurosurgeons, radiologists, anthropologists and forensic pathologists.

Keywords: Middle Meningeal Artery, Asterion, Glabella

Corresponding Author: Ananya Priya, Post Graduate, Department of Anatomy, Christian Medical College, Ludhiana, Punjab, India. E-mail: ananyapriya@ymail.com

Received: 30 September 2020

Revised: 02 November 2020

Accepted: 09 November 2020

Published: 22 December 2020

\section{Introduction}

Four bones meet at sutural junction in floor of temporal fossa to form pterion i.e. frontal bone and parietal bone superiorly and greater wing of sphenoid bone and squamous temporal bone inferiorly. ${ }^{[1]}$ Usually the group of sutures is $\mathrm{H}$-shaped but variations occur and epipteric bone may be present. The centre of pterion lies approximately $4 \mathrm{~cm}$ above the zygomatic arch and $3 \mathrm{~cm}$ behind the zygomatic process of the frontal bone. In this region the frontal branch of the middle meningeal artery lies in a groove on the inside of this bone and it is liable to be torn in fractures. ${ }^{[2]}$ This is a major landmark in anthropometry because it overlies the middle meningeal artery (anterior branch) and Sylvian fissure of the cerebral hemisphere. ${ }^{[1]}$

It is essential to know the surface anatomy of pterion for correct positioning of burr-hole in pterional craniotomy done for removal of pituitary tumours. In archaeological studies and forensic specimens, the pterion serves as as an important guide for age estimation in suture closure methodology of cranium. ${ }^{[3]}$ If wormian bones are present in the pterion region it may give a false impression of fracture and also sometimes real fracture may be interpreted as epipteric bone. Hence this must be known to radiologists. Knowledge about shape and location of pterion is of utmost important for neurosurgeons, anthropologists and forensic pathologists.

\section{Subjects and Methods}

Seventy dry skulls of adult humans irrespective of their age and sex were studied.

\section{Inclusion criteria:}

The present study included whole skulls and those in which vault of skull were cut but pterion and fronto-zygomatic suture were intact.

\section{Exclusion criteria:}


Skulls in which the shape of pterion was unclear due to damage or abnormal synostosis were excluded.

The shape of pterion was observed bilaterally and classified according to Murphy's classification. ${ }^{[4]}$ In order to measure distances from pterion to various bony landmarks, first centre of pterion was determined by using perpendicular bisectors theorem with the help of compass and lead pencil.

In sphenoparietal type of pterion, the suture between sphenoid and parietal bone was used as segment to find out the centre of pterion. One end of this suture was taken as centre, compass was placed here and arcs having more than half the length of the suture were drawn above and below. Then another end of the suture was taken as centre and arcs were drawn above and below. The point where both arcs intersected was joined by a thread. The line obtained was again intersected using perpendicular bisectors, the point where both these lines intersected were taken as centre of pterion.

In frontotemporal type of pterion, the suture between the frontal and temporal bone was used as segment. This segment was intersected using perpendicular bisectors theorem. In epipteric type of pterion, the point where frontosphenoidal and parietotemporal sutures meets the wormian bone was taken as centre and arcs were drawn taking radius more than half of length of wormian bone above and below.

In stellate type of pterion the point where all four bones meet was considered as midpoint of pterion.

Distances were measured in millimeter using digital Vernier caliper from midpoint of pterion to

i) Frontozygomatic suture

ii) Middle of zygomatic arch

iii) Tip of mastoid process

iv) Glabella

v) Antero-superior margin of external acoustic meatus

vi) Asterion.

The student's t-test was applied to compare right and left side of the skull. The p-value $>0.05$, this was considered not significant. The mean \pm SD were calculated for various distances measured. Percentage of various types of pterion was calculated [Table 1]. Data was scrutinized using SPSS version 16.0.

\section{Results}

The present study showed that Sphenoparietal type was the commonest. Second common type was atypical followed by epipteric and stellate. Frontotemporal type of pterion was absent. [Figure 1-5]

The distance from the midpoint of pterion to various bony landmarks on skull was measured to find out the exact location

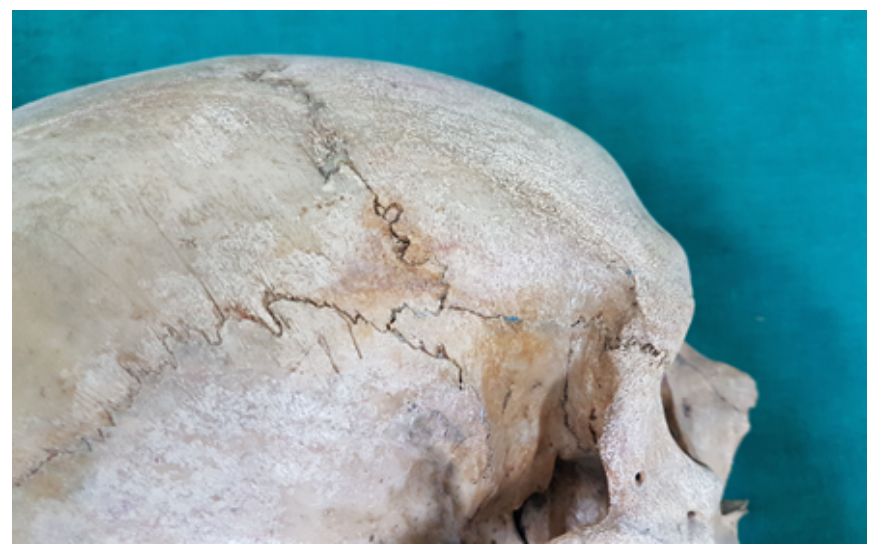

\section{Figure 1: Shape of pterion-Sphenoparietal type}

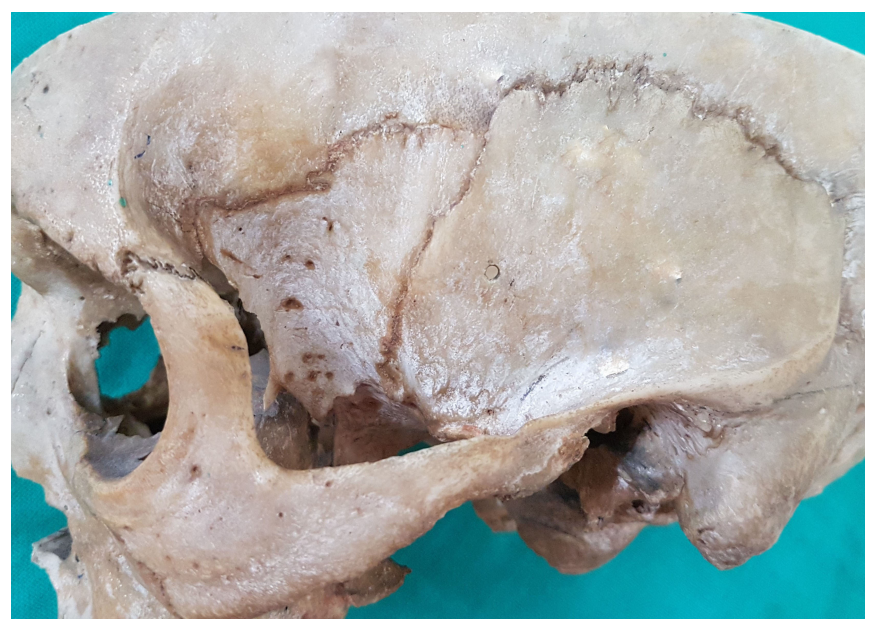

Figure 2: Shape of pterion-Atypical type

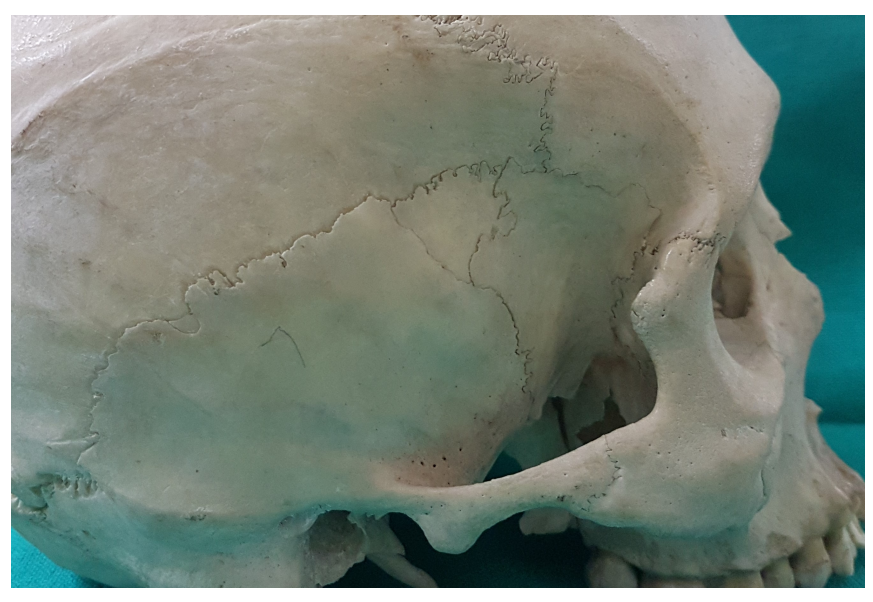

Figure 3: Shape of pterion-Epipteric type 


\begin{tabular}{|llll}
\hline Table 1: Percentage of types of pterion according to side & & \\
\hline Types of Pterion & Right Side $(\mathbf{n}=\mathbf{7 0})$ in $\%$ & Left Side $(\mathbf{n}=\mathbf{7 0})$ in $\%$ & Both Sides $(\mathbf{n}=\mathbf{1 4 0})$ in \% \\
\hline Sphenoparietal & $64.28 \%$ & $60 \%$ & $62.85 \%$ \\
\hline Atypical & $22.85 \%$ & $22.85 \%$ & $22.85 \%$ \\
\hline Epipteric & $11.42 \%$ & $14.28 \%$ & $12.85 \%$ \\
Stellate & $1.42 \%$ & $1.42 \%$ & $1.42 \%$ \\
\hline Frontotemporal & $0 \%$ & $0 \%$ & $0 \%$ \\
\hline
\end{tabular}

\begin{tabular}{|lll}
\hline Table 2: Mean distances from midpoint of pterion to various bony landmarks & \\
\hline $\begin{array}{l}\text { Distances from midpoint of pterion } \\
\text { to }\end{array}$ & Right Side (Mean \pm S.D) in mm & Left Side (Mean \pm S.D) in mm \\
\hline $\begin{array}{l}\text { Posterior aspect of frontozygomatic } \\
\text { suture }\end{array}$ & $31.68 \pm 5.58$ & $31.18 \pm 5.82$ \\
\hline $\begin{array}{l}\text { Midpoint of zygomatic arch } \\
\text { Asterion }\end{array}$ & $38.86 \pm 3.63$ & $37.84 \pm 3.99$ \\
\hline $\begin{array}{l}\text { Anterosuperior margin of external } \\
\text { acoustic meatus }\end{array}$ & $53.55 \pm 7.22$ & $85.53 \pm 6.88$ \\
\hline $\begin{array}{l}\text { Glabella } \\
\text { Tip of mastoid process }\end{array}$ & $77.24 \pm 6.93$ & $51.37 \pm 3.39$ \\
\hline
\end{tabular}

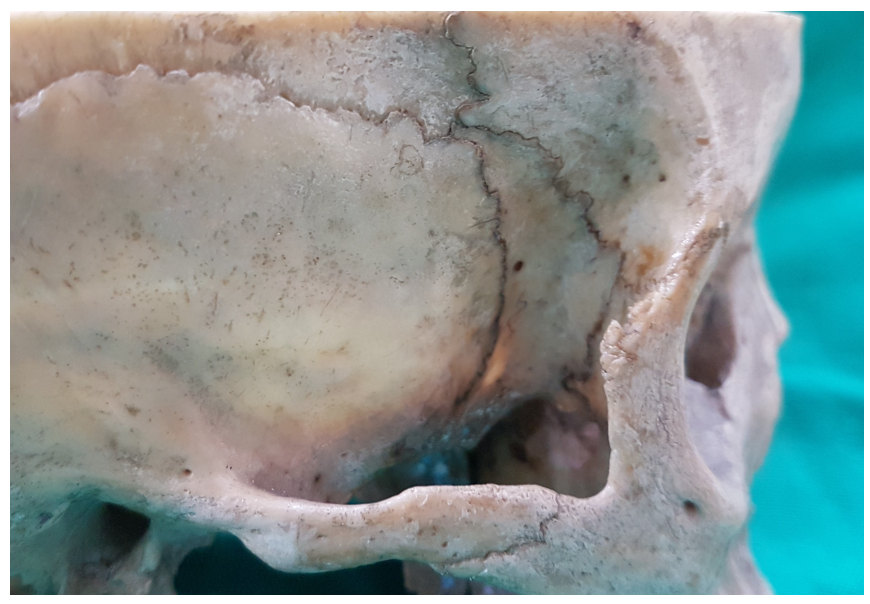

Figure 4: Shape of pterion- Stellate type

of pterion on the skull. The mean distances were tabulated in [Table 2].

\section{Discussion}

Comprehension of the shape, location and relation of pterion to various bony landmark of skull is significant for neurosugeons while performing minimally invasive surgeries. The most common transcranial approach for removal of pituitary tumors is pterional or frontosphenotemporal craniotomy.

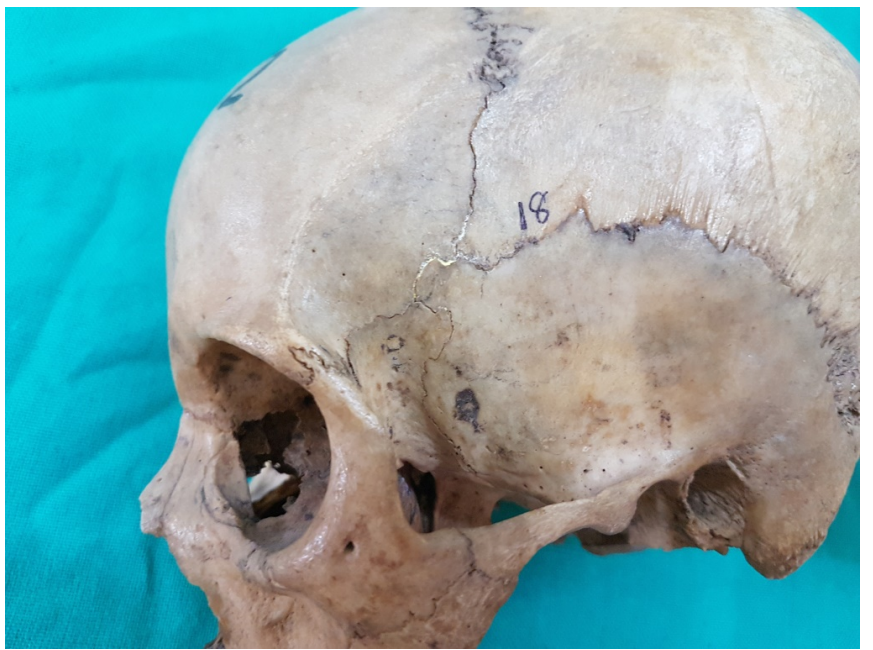

Figure 5: Shape of pterion- Fronto-temporal type

It was made popular by Yasargil as the most widely used transcranial approach in neurosurgery for intracranial aneurysms nowadays. It provides direct accessibility to sella turcica and permits extraction of large pituitary tumors with minimal brain retraction. It is also the approach of choice for tumors such as a prefixed chiasma as it can be resected safely below the optic chiasma. ${ }^{[5]}$ Therefore, the accurate location of pterion is mandatory. We took in consideration the Murphy's classification of the pterion. Murphy et al reported 
that variations in shape of pterion are most likely due to environmental and genetic factors. ${ }^{[4]}$

The most common type of pterion in our study was sphenoparietal type which was similar to all other past studies. During evolution of primates, the anterosuperior part of the squamous temporal bone of lower primates became detached and in humans it fused with the posterosuperior angle of the greater wing of the sphenoid bone, thereby changing the shape of pterion from the frontotemporal type of lower primates to the sphenoparietal type of humans. Second common type of pterion found was atypical type which was not seen in any other past studies except by Satpute et al, ${ }^{[6]}$ who observed $1.76 \%$ atypical type in his study. Third common pterion type observed in the present study was epipteric type which was much less in comparison to other studies done on north Indian population, whereas it was similar to studies done on west indian population by Zalawadia et al. ${ }^{[7]}$ Next common type of pterion was stellate type which was similar in all indian studies, but in a study done by Lee et al, ${ }^{[8]}$ on Korean population it was absent. The frontotemporal type was absent in the present study, which was same as that of Lee et al. ${ }^{[8]}$ [Table 3]

Similarities were observed in the location of pterion as the mean distance from the midpoint of pterion to several bony landmarks and was found similar to the studies done in other indian population as well as that done in a study done by Aymen et al in Saudi Arabia. ${ }^{[14]}$

There were regional differences in these distances when compared between Indian and Turkish population. In a study done in solan by Gindha et al, ${ }^{[13]}$ the distance from centre of pterion to frontozygomatic suture was very high as compared to the present study this can be explained based on the fact that the development of skull depend on genetics of particular race. [Table 4]

\section{Conclusion}

We concluded that sphenoparietal type is the most commonly found type and frontotemporal type was usually either absent or less common in human population in all ethnic groups, this fact can be used by anthropologists to study the bony remains. Mean linear distances of pterion from various cranial bony landmarks derived in this study will be of great help in determining the exact point for burr-hole positioning while performing craniotomy. Also, more no. of epipteric bone in pterion region is an indication of rapidly growing cranium as seen in hydrocephalus.
- Acknowledgment: All the authors acknowledge the help that we received from authors of various articles which are cited in the reference of this manuscript. We are very grateful to all the technical help involved in this study.

\section{References}

1. Kamath VG, Hande M. Reappraising the neurosurgical significance of the pterion location, morphology, and its relationship to optic canal and sphenoid ridge and neurosurgical implications. Anat Cell Biol. 2019;52(4):406-413. Available from: https://dx.doi.org/10.5115/acb.18.200.

2. Yu J, Guo Y, Xu B, Xu K. Clinical importance of the middle meningeal artery: A review of the literature. Int $\mathrm{J}$ Med Sci. 2016;13(10):790-799. Available from: https://dx.doi.org/10. $7150 /$ ijms. 16489 .

3. Ilknur A, Mustafa KI, Sinan B. A Comparative Study of Variation of the Pterion of Human Skulls from 13th and 20th Century Anatolia. Int J Morphol. 2009;27(4):12911299. Available from: https://dx.doi.org/10.4067/s071795022009000400051.

4. Murphy T. The pterion in Australian aborigine. Am J Phys Anthropol. 1956;14:225-229. Available from: https://doi.org/ 10.1002/ajpa.1330140218.

5. Recinos PF, Goodwin CR, Brem H, Hinojosa AQ. Transcranial Surgery for pituitary Macroadenomas. In: AQ H, editor. Sweet operative neurosurgical techniques: Indications, methods, and results. vol. 1. Elsevier; 2012. p. 280-90.

6. Satpute C, Wahane A. To study the morphology of pterion in dry human skull in Vidarbha region. Int J Sci Res. 2013;4(1):2171-2173.

7. Zalawadia DA, Vadgama DJ, Ruparelia DS, Patel DS, Patel DSV. Morphometric Study of Pterion In Dry Skull Of Gujarat Region. NJIRM. 2010;1(4):25-29.

8. Lee UY, Park DK, Kwon SO, Paik DJ, Han SH. Morphological analysis of the pterion in Korean. Korean J Phys Anthropol. 2001;14(4):281-290.

9. Agarwal AK, Singh PJ, Gupta SC, Gupta CD. Pterion formation and its variations in the skulls of Northern India. Anthropol Anz. 1980;38:265-274.

10. Saxena RC, Bilodi A, Mane SS, Kumar A. Study of pterion in skulls of awadh area-in and around Lucknow. Kathmandu Univ Med J. 2003;1:32-33.

11. Mwachaka PM, Hassanali J, Odula P. Sutural morphology of the pterion and asterion among adult Kenyans. Braz J Morphol Sci. 2009;26:4-7.

12. Seema, Mahajan A. Pterion Formation in North Indian Population: An Anatomico-Clinical Study. Int J Morphol. 2014;32(4):1444-1448. Available from: https://dx.doi.org/10. 4067/s0717-95022014000400050.

13. Gindha GS, Ns M, Agarwal R. Morphometric Study of Pterion in Dry Human Skull Bone in North Indian Population. Hum Biol Rev. 2017;6(1):1-9. 
Table 3: Comparison of types of pterion in various studies

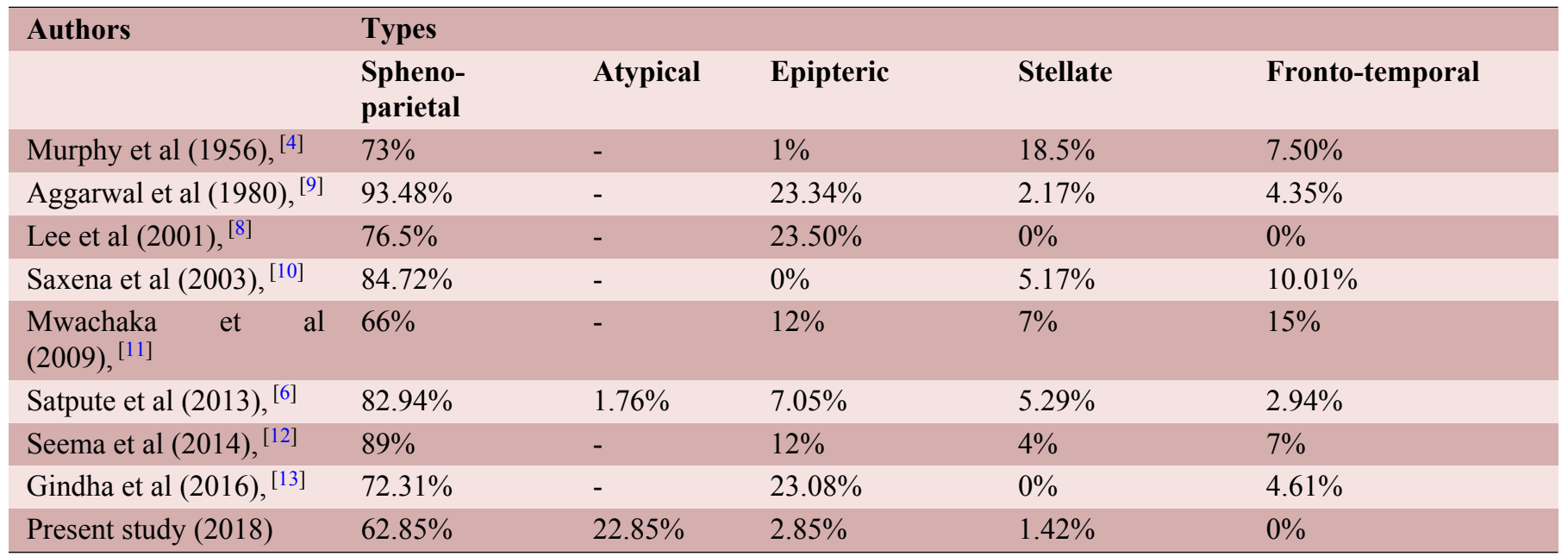

Table 4: Comparison of mean distances from the midpoint of pterion to several bony landmarks

\begin{tabular}{|c|c|c|c|c|c|c|c|c|}
\hline \multirow[t]{3}{*}{ Author } & \multicolumn{8}{|c|}{ Distance(Mean \pm S.D) in $\mathbf{m m}$} \\
\hline & \multicolumn{2}{|l|}{ P-FZ } & \multicolumn{2}{|l|}{ P-ZA } & \multicolumn{2}{|l|}{ P-EAM } & \multicolumn{2}{|l|}{ P-Ms } \\
\hline & Right & Left & Right & Left & Right & Left & Right & Left \\
\hline $\begin{array}{l}\text { Ilknur A et al } \\
(2009),{ }^{[3]}\end{array}$ & $35 \pm 5.0$ & $35 \pm 5.0$ & $39 \pm 9.3$ & $39 \pm 5.0$ & $58 \pm 4.0$ & $51 \pm 4.0$ & $77 \pm 5.0$ & $78 \pm 5.0$ \\
\hline $\begin{array}{l}\text { Aksu F et al } \\
(2014),{ }^{[15]}\end{array}$ & $31.80 \pm 4.5$ & $31.44 \pm 4.7$ & $40.02 \pm 4.06$ & $39.88 \pm 4.0$ & $53.29 \pm 4.5$ & $56.22 \pm 4.6$ & $82.48 \pm 5.45$ & $81.81 \pm 5.5$ \\
\hline $\begin{array}{l}\text { Seema et al } \\
(2014),{ }^{[12]}\end{array}$ & $31.0 \pm 4.4$ & $34.0 \pm 4.0$ & $41.0 \pm 4.5$ & $44.0 \pm 3.2$ & - & - & - & - \\
\hline $\begin{array}{l}\text { Prasad H et al } \\
(2015),[16]\end{array}$ & $32 \pm 3.9$ & $31.1 \pm 4.0$ & $37.1 \pm 3.9$ & $36.8 \pm 3.5$ & $51.9 \pm 5.9$ & $51.2 \pm 3.2$ & $80.2 \pm 5.8$ & $81.3 \pm 4.5$ \\
\hline $\begin{array}{l}\text { Aymen A et } \\
\text { al (2016), }{ }^{[14]}\end{array}$ & $32.3 \pm 3.9$ & $31.2 \pm 5.0$ & $36.3 \pm 3.5$ & $37.3 \pm 3.1$ & $51.8 \pm 5.6$ & $51.3 \pm 3.3$ & $81.3 \pm 5.3$ & $81.2 \pm 4.4$ \\
\hline $\begin{array}{l}\text { Gindha et al } \\
(2016),{ }^{[13]}\end{array}$ & $38.71 \pm 3.1$ & $36.29 \pm 3.7$ & $39.00 \pm 2.5$ & $37.00 \pm 3.3$ & - & - & - & - \\
\hline $\begin{array}{l}\text { Kulkarni P et } \\
\text { al (2017), }{ }^{[17]}\end{array}$ & $29.81 \pm 4.4$ & $29.81 \pm 4.0$ & $37.16 \pm 3.77$ & $37.56 \pm 3.7$ & $53.40 \pm 7.2$ & $53.57 \pm 6.7$ & $80.35 \pm 3.4$ & $80.96 \pm 3.7$ \\
\hline Present study & $31.68 \pm 5.5$ & $31.18 \pm 5.8$ & $38.86 \pm 3.63$ & $37.84 \pm 3.9$ & $51.70 \pm 3.2$ & $51.37 \pm 3.4$ & $80.77 \pm 6.10$ & $79.59 \pm 5.7$ \\
\hline
\end{tabular}

14. Warille AA, Mandloi RS. Measurement of the various identifiable bony landmarks from the center of pterion in human skulls from Indian Population. Int J Health Sci Res. 2016;6(2):133-137.

15. Aksu F, Akyer SP, Kale A, Geylan S, Gayretli O. The Localization and Morphology of Pterion in Adult West Anatolian Skulls. Arch Craniofac Surg. 2014;25(4):1488-1491. Available from: https://dx.doi.org/10.1097/scs.0000000000000790.

16. Prasad H, Bezbaruah NK, Mishra A, Mishra PP. Morphometric analysis of pterion: A clinic-anatomical study in north Indian dry skulls. IJMHS. 2015;5(5):201-205.

17. Kulkarni P, Sukre S, Muley M. Morphometric study of pterion in dry adult human skulls. Int J Anat Res. 2017;5(3.3):4365-68. 
Copyright: (C) the author(s), 2020. It is an open-access article distributed under the terms of the Creative Commons Attribution License (CC BY 4.0), which permits authors to retain ownership of the copyright for their content, and allow anyone to download, reuse, reprint, modify, distribute and/or copy the content as long as the original authors and source are cited.

How to cite this article: Priya A, Jain A. Morphological and Morphometric Study of Pterion in Adult Dry Human Skulls. Acad. Anat. Int. 2020;6(2):63-68.

DOI: dx.doi.org/10.21276/aanat.2020.6.2.14

Source of Support: Nil, Conflict of Interest: None declared. 